\title{
DESCOLONIZAÇÃO METAFÍSICA: ESBOÇO DE MANIFESTO CONTRA-FILOSÓFICO
}

Marco Antonio Valentim ${ }^{1}$

\section{Resumo}

Este breve ensaio toma como ponto de partida a hipótese de que há um vínculo constitutivo do discurso filosófico moderno com o etnocídio, exemplificado pelo cosmopolitismo kantiano enquanto paradigma do "racismo europeu" (Deleuze \& Guattari). Buscam-se os fundamentos metafísicos desse vínculo com apoio no diagnóstico do processo colonial produzido por Lévi-Strauss e, sobretudo, por Fanon e Césaire. Sustenta-se que, de um ponto de vista metafísico, colonização e descolonização se caracterizam por modos divergentes de realizar a diferença ontológica de mundo entre povos distintos. O ensaio esboça, por fim, uma problematização do papel histórico da filosofia na instituição da colonialidade.

Palavras-chave: cosmopolitismo; racismo; ontologia; mundo; descolonização.

\section{METAPHISIC DESCONLONIZATION: OUTILE OF COUNTER- PHILOSOPHICAL MANIFESTO}

\begin{abstract}
This short essay takes as starting point the hypothesis according to which there is a constitutive bond between the philosophical discourse of modernity and ethnocide, exemplified by Kantian cosmopolitism as
\end{abstract}


paradigm of "European racism" (Deleuze \& Guattari). The metaphysical foundations of this bond are sought with support of the diagnosis of the colonial process produced by Lévi-Strauss and, mainly, Fanon, and Césaire. It is argued that, from a metaphysical point of view, colonization and decolonization are characterized by divergent modes of accomplishing the ontological difference of world between distinct people. Lastly, the essay outlines a problematization of the historical role played by philosophy in the institution of coloniality.

Keywords: cosmopolitism; racism; ontology; world; decolonization.

A dialética que introduz a necessidade de um ponto de apoio para a minha liberdade expulsa-me de mim próprio. Ela rompe minha posição irrefletida. Sempre em termos de consciência, a consciência negra é imanente a si própria. Não sou uma potencialidade de algo, sou plenamente o que sou. Não tenho de recorrer ao universal. No meu peito nenhuma probabilidade tem lugar. Minha consciência negra não se assume como a falta de algo. Ela é. Ela é aderente a si própria.

(Fanon, Pele negra, máscaras brancas.)

\section{Filosofia e etnocídio ${ }^{2}$}

Uma tese forte e polêmica, embora nada inverossímil, é proposta por Viveiros de Castro para resumir o diagnóstico em que se baseia o projeto de uma antropologia animada pelo propósito de "descolonização permanente do pensamento" (Viveiros de Castro, 2015, p. 32) - uma antropologia que, comprometida com a "descrição das condições de autodeterminação ontológica dos coletivos", demandaria "um outro modo de criação de conceitos que não o 'filosófico', no sentido histórico-acadêmico do termo" (idem, p. 24-25, 32). Essa tese diz: "A metafísica ocidental é a fons et origo de toda espécie de colonialismo" (idem, p. 27).

No presente, buscarei comentá-la, por assim dizer, em free form, articulando improvisadamente vários discursos, tanto harmônicos quanto desarmônicos entre si, com o objetivo principal de elucidar a conexão neles estabelecida ou pressuposta entre metafísica e colonialidade. Espero, com isso, tecer uma breve indicação sobre o lugar do discurso filosófico, tomado mais precisamente em sua expressão ontológica, na "guerra dos mundos" (Latour, 2002) conjurada pelo processo colonial.

Texto da comunicação apresentada no II COPENE SUL - Congresso de Pesquisadores(as) Negros(as) da Região Sul, na mesa-redonda "Interfaces da descolonização filosófica na diáspora africana", realizada no dia 22 de julho de 2015 em Curitiba. Agradeço a Luís Thiago Freire Dantas e Roberto Jardim da Silva o generoso convite para participar dessa mesa. Ao primeiro agradeço também a interlocução sobre o tema da comunicação e a indicação de várias referências bibliográficas de que procurei fazer uso. Além disso, o texto beneficiou-se enormemente do diálogo com Pedro Augusto Pereira Gonçalves, no contexto da produção de sua monografia de conclusão de curso. 
O que entendo aqui por filosofia não equivale àquela sublime capacidade "crítica" de abstração e enlevo espiritual que se supõe compartilhada - se não de fato, pelo menos de direito - por todos os sujeitos e povos (como dizia Descartes, não sem profunda e senhorial ironia: "a coisa do mundo melhor partilhada"). Ao invés disso, o que procuro entender por isso corresponde, majoritariamente, ao modo de pensamento e expressão de um povo bem determinado, aquele que pretendeu erigir-se frente a todos os demais não apenas como único ou primeiro, mas sobretudo como universalmente necessário: filosofia, no sentido do discurso do povo universal, é a pretensão de constituir a unidade do mundo para todos, ou seja, "oferecendo generosamente deixar os outros entrarem sob a condição de que abandonem à porta tudo o que lhes é caro: seus deuses, suas almas, seus objetos, seus tempos e seus espaços, em suma, sua ontologia" (Latour, 2002, p. 30). Destinada à formação e construção de um mundo universal, própria e exclusivamente humano, essa filosofia consiste, ao mesmo tempo, na obra de empobrecimento e destruição de outros mundos, diferentemente humanos e não-humanos (cf. Valentim, 2013): "Nada mais consequente, entre nós", diz Sartre no prefácio a Os condenados da terra, "do que um humanismo racista, pois o europeu só pôde fazer-se homem fabricando escravos e monstros" (Sartre, 2005, p. 43). ${ }^{3}$

Afinal, se "a espiritualidade do etnocídio é a ética do humanismo" (Clastres, 2011, p. 80), ${ }^{4}$ como se poderia evitar a suspeita, talvez mesmo a certeza, de que, no trabalho filosófico de universalização e normatização do pensamento, isto é, de "dissolução do múltiplo no Um" (idem, p. 83), domina um impulso etnocida?

\section{Ontologia branca}

Tome-se o caso exemplar de Kant, o ilustre transeunte por cuja passagem muitos de nós continuam acertando seus relógios... Sua

Seja lembrado, no entanto, que Fanon critica duramente a perspectiva histórica na qual Sartre enquadra a questão da negritude: "Demonstravam-me que minha iniciativa era apenas um pólo na dialética [...]" (Fanon, 2008, p. 120 e ss.). O trecho de Pele negra, máscaras brancas citado como epígrafe é uma conclusão voltada justamente contra a pretensa universalidade da "razão dialética". E a mesma concepção é alvo de uma crítica mordaz por Lévi-Strauss no capítulo final de $O$ pensamento selvagem: "Reduzindo-os [os outros] ao estado de meios suficientemente bons para satisfazer a seu apetite filosófico, a razão histórica entrega-se a uma espécie de canibalismo intelectual, que, aos olhos do etnógrafo, é muito mais revoltante que o outro" (Lévi-Strauss, 1989, p. 286, nota 83).

4 Trata-se da tese clastreana sobre o ideal iluminista de conversão do selvagem em civilizado: "O horizonte no qual se destacam o espírito e a prática etnocidas é determinado segundo dois axiomas. O primeiro proclama a hierarquia das culturas: há as que são inferiores e as que são superiores. Quanto ao segundo, ele afirma a superioridade absoluta da cultura ocidental. Portanto, esta só pode manter com as outras, e em particular com as culturas primitivas, uma relação de negação. Mas trata-se de uma negação positiva, no sentido de que ela quer suprimir o inferior enquanto inferior para içá-lo ao nível do superior. Suprime-se a indianidade do índio para fazer dele um cidadão brasileiro. Na perspectiva de seus agentes, o etnocídio não poderia ser, conseqüentemente, um empreendimento de destruição: ao contrário, é uma tarefa necessária, exigida pelo humanismo inscrito no núcleo da cultura ocidental" (Clastres, 2011, p. 80). 
filosofia ocupa ainda hoje o centro espiritual do Ocidente moderno, e não raro alguém se espanta de que o seu universalismo moral possa estar acompanhado, no mesmo corpus textual, de um racismo até mesmo profético: “Todas as raças serão erradicadas (americanos e negros não podem governar a si mesmos. Servem, portanto, apenas como escravos), menos a dos brancos", os quais "contêm todos os móbeis da natureza em afetos e paixões, todos os talentos, todas as disposições à cultura e civilização, e podem assim tanto obedecer quanto dominar", sendo "os únicos que sempre progridem à perfeição" (Kant, 1923, p. 878; AA XV/2, 1520). . "Erro ou má fé" (Sartre, 2005, p. 43)? Paradoxo?! Afinal, como o filósofo da Fundamentação da metafísica dos costumes, que formulara o imperativo segundo o qual todas as pessoas, à diferença das meras coisas, devem ser tratadas como fins em si mesmos, poderia ter professado uma doutrina tão perversa? Tratar-se-ia, como se costuma dizer, simplesmente da opinião infeliz de "um homem de seu tempo"?

Ao pensar assim, rejeita-se com pressa indevida a hipótese sumamente indigesta de que haja uma conexão sistemática, em rigoroso sentido kantiano, entre universalismo e etnocídio, humanismo e racismo, cosmopolitismo e colonialismo. Ora, como é sabido, justamente em sua formalidade extrema, a moralidade universal impõe condições necessárias para um sujeito ser pessoa digna de consideração (pois nem todos os homens, segundo a espécie, são pessoas, segundo a dignidade moral), condições que não seriam satisfeitas por todos aqueles (americanos, negros, indianos, etc.; cf. Kant, 1923, p. 875-880), que resistem à Aufklärung, em virtude de suas "naturezas-culturas" (Latour, 1994, p. 102), ou seja, de seus próprios mundos. Sobretudo, como também se sabe, a lógica mesma do cosmopolitismo postula, na base do progresso civilizacional, "sub-humanos" (Untermenschen), ${ }^{6}$ portadores da "barbárie, grosseria e degradação bestial da humanidade" (Kant, 2008, p. 32; trad. modif.), por cuja existência em "puro estado de natureza" o homem cosmopolita se vê "continuamente ameaçado", e contra a qual pode, por direito e dever, insurgir-se. ${ }^{7}$ Donde a difícil porém forçosa constatação: de um ponto de vista extra-cosmopolita, a razão pura é branca e... racista. ${ }^{8}$

Sobre o uso desse termo polêmico na interpretação de Kant, cf. Mills, 2005.

7 "Mas o homem (ou o povo) no puro estado de natureza tira de mim esta segurança e me lesa já por esse mesmo estado, na medida em que está ao meu lado, ainda que não de fato (facto), pela ausência de leis de seu Estado, pelo que eu sou continuamente ameaçado por ele, e posso forçá-lo ou a entrar comigo em um Estado comum legal ou a retirar-se de minha vizinhança" (Kant, 2008, p. 23).

8 Para uma discussão mais profunda acerca do "lugar sistemático" do racismo na filosofia kantiana, cf. Eze, 1997; Bernasconi, 2003; e Mills, 2005. Para uma leitura refratária a essa tese interpretativa, cf., por exemplo, Hill \& Boxill, 2000; e Terra, 2010. No que se refere a este último, a contra-argumentação (bastante elíptica, para dizer o mínimo) limita-se a constatar que "as passagens com teor racista indicam o tipo de fonte empírica de que Kant dispunha e não têm consequências em sua filosofia" (Terra, 2010, p. 139). Além de negligenciar o fato de que tais passagens acham-se incrustadas no próprio corpo sistemático da filosofia kantiana (cf., por exemplo, Kant, 2002, p. 221/B 300), pressupõe-se assim que o universalismo filosófico seja 
Olhando-se mais de perto, um prejuízo propriamente transcendental parece garantir o nexo a priori entre humanismo e racismo, tal como exemplificado pela filosofia kantiana:

O racismo europeu como pretensão do homem branco nunca procedeu por exclusão nem atribuição de alguém designado como Outro: seria antes nas sociedades primitivas que se apreenderia o estrangeiro como um "outro". O racismo procede por determinação das variações de desvianças, em função do rosto Homem branco que pretende integrar em ondas cada vez mais excêntricas e retardadas os traços que não são conformes, ora para tolerá-los em determinado lugar e em determinadas condições, em certo gueto, ora para apagá-los no muro que jamais suporta a alteridade (é um judeu, é um árabe, é um negro, é um louco..., etc). Do ponto de vista do racismo, não existe exterior, não existem as pessoas de fora. Só existem pessoas que deveriam ser como nós, e cujo crime é não o serem. A cisão não passa mais entre um dentro e um fora, mas no interior das cadeias significantes simultâneas e das escolhas subjetivas sucessivas. O racismo jamais detecta as partículas do outro, ele propaga as ondas do mesmo até à extinção daquilo que não se deixa identificar (ou que só se deixa identificar a partir de tal ou qual desvio) (Deleuze \& Guattari, 1996, p. 45-46).

O mencionado prejuízo advém da postulação do caráter ontologicamente derivado da alteridade (como "variação desviante"), sem o que a pretensão a um pensamento universal e necessário - notadamente, a ideia de uma natureza humana - não poderia sequer fazer sentido: extrapolando-se outra tese clastreana, "a negação etnocida do Outro" é o que torna possível a "identificação a si" (Clastres, 2011, p. 79) requerida para a instituição tanto do entendimento transcendental ${ }^{9}$ quanto do Estado cosmopolita. ${ }^{10} \mathrm{E}$, com efeito, o postulado ontológico-político

etnológica e politicamente (!) neutro, quando, precisamente devido a essa pretensão - a de "uma paz transcendente com o poder de exigir a todo aquele que diverge que se reconheça como expressão puramente individual do que constitui o ponto de convergência de todos" (Stengers, 2005, p. 995) -, tal universalismo se configura ele mesmo como dispositivo de exclusão (ou "inclusão exclusiva", como formula Agamben). Ademais, testemunha em favor disso a orientação inequivocamente habermasiana com que o intérprete julga poder dispensar a "suspeição generalizada que se quer radical, mas que termina por se autodestruir por contradições performativas" ("Serve-se da razão para criticar radicalmente a razão, da democracia contra democracia, da tolerância contra a tolerância"; Terra, 2010, p. 140). Segundo esse modo de pensar, que advoga, contra toda variação antropológica originária, a universalidade normativa da razão, uma divergência genuína (não só de pensamento, mas também de mundo) torna-se, no limite, impossível ou nula: a alteridade cultural radical seria uma "contradição performativa". Com efeito, como afirmam Deleuze e Guattari (ver acima), "do ponto de vista do racismo [no caso, do cosmopolitismo], não existe exterior, não existem as pessoas de fora"... Por fim, sobre o caráter eminentemente exclusivo da universalidade kantiana, cf. Gonçalves, 2015.

9 "[...] aquela autoconsciência que, ao produzir a representação eu penso, que deve poder acompanhar todas as demais e é una e idêntica em toda consciência, não pode jamais ser acompanhada por nenhuma outra" (Kant, 1980, p. 85, B132).

10 "Portanto, o postulado que serve de fundamento a todos os artigos seguintes [para a instituição da paz perpétua entre os Estados] é: todos os homens que podem influenciar-se reciprocamente têm de pertencer a alguma constituição civil" (Kant, 2008, p. 23). 
da inexistência de Outrem (cujas origens remontam, sem dúvida, à ciência aristotélica do ente enquanto ente), constitui nada menos que o fundamento metafísico da experiência colonial:

Enquanto o negro estiver em casa não precisará, salvo por ocasião de pequenas lutas intestinas, confirmar seu ser diante de um outro. Claro, bem que existe o momento de "ser-para-o-outro", de que fala Hegel, mas qualquer ontologia torna-se irrealizável em uma sociedade colonizada e civilizada. Parece que este fato não reteve suficientemente a atenção daqueles que escreveram sobre a questão colonial. Há, na Weltanschauung de um povo colonizado, uma impureza, uma tara que proíbe qualquer explicação ontológica. Pode-se contestar, argumentando que o mesmo pode acontecer a qualquer indivíduo, mas, na verdade, está se mascarando um problema fundamental. A ontologia, quando se admitir de uma vez por todas que ela deixa de lado a existência, não nos permite compreender o ser do negro. Pois o negro não tem mais de ser negro, mas sê-lo diante do branco. Alguns meterão na cabeça que devem nos lembrar que a situação tem um duplo sentido. Respondemos que não é verdade. Aos olhos do branco, o negro não tem resistência ontológica. De um dia para o outro, os pretos tiveram de se situar diante de dois sistemas de referência. Sua metafísica ou, menos pretensiosamente, seus costumes e instâncias de referência foram abolidos porque estavam em contradição com uma civilização que não conheciam e que lhes foi imposta (Fanon, 2008, p. 103-104).

Segundo Fanon, há, pois, um conflito de mundos ou "sistemas de referência" que torna outrem (no caso, o negro) inacessível, ou ainda, inexistente (sem "resistência") para a ontologia branca. Essa ontologia, a Ontologia, fissurada pela identidade essencial do ente consigo mesmo, isto é, pela autenticidade ou propriedade como valor supremo, torna-se incapaz, e por decisão, de compreender o "ser" de outrem e, inclusive, o seu próprio ser-por-outrem, a sua impropriedade de origem:

Não há culturas inautênticas, pois não há culturas autênticas. Não há, aliás, índios autênticos. Índios, brancos, afro-descendentes, ou quem quer que seja - pois autêntico não é uma coisa que os humanos sejam. Ou talvez seja uma coisa que só os brancos podem ser (pior para eles). A autenticidade é uma autêntica invenção da metafísica ocidental, ou mesmo mais que isso - ela é seu fundamento, entenda-se, é o conceito mesmo de fundamento, conceito arquimetafísico. Só o fundamento é completamente autêntico; só o autêntico pode ser completamente fundamento. Pois o Autêntico é o avatar do Ser, uma das máscaras utilizada pelo Ser no exercício de suas funções monárquicas dentro da onto-teo-antropologia dos brancos (Viveiros de Castro, 2008, p. 148). ${ }^{11}$ 
Assim, essa "onto-teo-antropologia" recalca a situação intensamente política em que se encontra desde logo implicada e de onde extrai seu sentido mais concreto: a "colonialidade do Ser" (Maldonado-Torres, 2008). Visado em sua dimensão metafísica, o colonialismo revela que o Ser mesmo - ao invés de, como se pretende, um lugar de necessária convergência e mediação (ou justamente por causa dessa pretensão) - consiste, tal qual a razão pura e sua paz perpétua, em um colossal impedimento à "autodeterminação ontológica" dos povos e, com isso, à possibilidade metafísico-política de outros mundos.

\section{Descolonização metafísica}

De fato, não há solo comum entre os mundos em conflito; não há mundo comum:

O mundo colonizado é um mundo cortado em dois. A linha de corte, a fronteira, é indicada pela caserna e pelos postos policiais. [...] A zona habitada habitada pelos colonizados não é complementar à zona habitada pelos colonos. Essas duas zonas se opõem, mas não a serviço de um unidade superior. Regidas por uma lógica puramente aristotélica [!], elas obecedem ao princípio da exclusão recíproca: não há conciliação possível, um dos termos é demais. [...] Esse mundo compartimentado, esse mundo cortado em dois, é habitado por espécies diferentes. [...] A espécie dirigente é primeiro aquela que vem de fora, aquela que não se parece com os autóctones, "os outros" (Fanon, 2008, p. 54-57).

É esse modo - dicotômico, hierárquico e sem reciprocidade - da diferença de mundo que a colonização torna maximamente patente: as "zonas" não se deixam compreender segundo uma "segundo o Um e certa natureza única" (se a lógica do conflito é aristotélica, a sua ontologia certamente não é); não há complementaridade, passagem nem troca; a "exclusão recíproca" manifesta uma incomensurabilidade irredutível; e esta atinge o sentido mesmo de humanidade, que se revela equívoco (o colonizador e o colonizado pertencem a "espécies diferentes").

Tal "linha de corte" é interpretada por Lévi-Strauss como sendo a obra da filosofia do homem ocidental dos "quatro últimos séculos": guiada pelo "mito da dignidade exclusiva da natureza humana", essa filosofia teria instaurado, com um só gesto de exclusão ("a mesma fronteira"), uma separação abissal entre humanidade e animalidade e uma outra, tão ou mais profunda, entre diferentes povos humanos

verdade só esteve com os nacionais. Nenhuma verdade absoluta, nenhum discurso sobre a transparência da alma pode abalar essa posição. À mentira da situação colonial, o colonizado responde com um mentira igual. A conduta é aberta com os nacionais, crispada e ilegível com os colonos. A verdade é aquilo que precipita o desmantelamento do regime colonial, é o que favorece a emergência da nação. O verdadeiro é aquilo que protege os indígenas e destrói os estranhos. No contexto colonial, não há conduta de verdade. E o bem é simplesmente tudo aquilo que faz mal a eles" (Fanon, 2005, p. 67). 
(Lévi-Strauss, 2013a, p. 53). “Será o animal o primeiro escravo, ou o escravo o primeiro animal?"12 Segundo Lévi-Strauss, a máquina antropológica do Ocidente moderno gira em ambos sentidos: especismo e racismo, enquanto aspectos mutuamente solidários de um único "ciclo maldito" (idem).

Contudo, a proximidade entre os diagnósticos de Fanon e Lévi-Strauss acerca do humanismo europeu não desmente uma discordância profunda quanto ao sentido político do colonialismo. Como se sabe, em "Raça e história" (do mesmo ano de Pele negra, máscaras brancas, 1952), o pensador francês defende, a fim de demonstrar a tese segundo a qual "todo progresso cultural é função de uma coalizão entre culturas" (Lévi-Strauss, 2013b, p. 395), que imperialismo e colonialismo constituem formas efetivas dessa progressiva coalizão:

Só pode haver exploração dentro de uma coalizão; entre os dois grupos, dominante e dominado, existem contatos e ocorrem intercâmbios. A um dado momento, e apesar da relação unilateral que aparentemente os une, deverão, consciente ou inconscientemente, conjugar suas apostas e, progressivamente, as diferenças que os opõem tenderão a diminuir. As melhorias sociais, de um lado, e a acessão gradual dos povos colonizados à independência, de outro, nos colocam diante do desenrolar desse fenômeno. E embora haja ainda um longo caminho pela frente em ambas direções, sabemos que as coisas caminham inevitavelmente nesse sentido (idem, p. 397).

Apesar da refutação cabal do primitivismo moderno empreendida por Lévi-Strauss nesse mesmo escrito, na qual se o denuncia como efeito de uma limitação etnocêntrica de perspectiva, é evidente certa herança kantiana na proposição desse cosmopolitismo moderado, digamos assim, "inclusivo".

Sob esse aspecto, Lévi-Strauss não poderia estar mais distante de Césaire, para quem "a Europa é indefensável" (Césaire, 1978, p. 14), no sentido de que "da colonização à civilização a distância é infinita" (idem, p. 15-16):

Nenhum contato humano, mas relações de dominação e de submissão que transformam o homem colonizador em criado, ajudante, comitre, chicote e o homem indígena em instrumento de produção. É a minha vez de enunciar uma equação: colonização = coisificação. Ouço a tempestade. Falam-me de progresso, de "realizações", de doenças curadas, de níveis de vida elevados acima de si próprios. Eu, eu falo de sociedades esvaziadas de si próprias, de culturas espezinhadas, de instituições minadas, de terras confiscadas, de religiões assassinadas, de magnificências artísticas aniquiladas, de extraordinárias possibilidades suprimidas (idem, p. 25). 
Como que respondendo a Lévi-Strauss, em lugar de progresso por coalizão, Césaire discerne no processo colonial uma operação fundamental de desumanização, que retroage, não obstante, sobre o seu próprio sujeito: habituado a "ver no outro o animal", o colonizador, ou seja, o homem cosmopolita, "tende objetivamente a transformar-se ele próprio em animal" (idem, p. 24) - com a notável diferença de que, em termos de desumanização, a distância entre o animal sub-humano a que o colonizado é reduzido pelo colonizador e o monstro desumano em que este se transforma "objetivamente" aos olhos daquele também parece não ser pouca.

Porém, o que faz com que Lévi-Strauss, crítico assíduo e contundente do humanismo moderno, tenha os olhos assim aparentemente fechados para a monstruosidade do colonialismo, permitindo-se enxergar progresso cultural aí mesmo onde, desde o outro lado, só se experimenta coisificação e animalização? ${ }^{13}$ Trata-se, talvez, daquela mesma pressuposição fundante da metafísica ocidental, a da unidade e identidade específicas da natureza humana, que as diferentes culturas não fariam senão configurar de diversas maneiras, "aparentemente" contraditórias (cf. Lévi-Strauss, 2013b, pp. 365, 398). É com base em tal substrato comum, universal, que se pode pretender que, apesar de suas ilusões mútuas a respeito, o colonizador e o colonizado partilhem da mesma humanidade, sendo capazes de uma progressiva coalizão através do próprio conflito colonial. Mas, ao mesmo tempo, essa pressuposição fundamental favorece a neutralização, sempre unilateral, da guerra dos mundos em curso, impondo um obstáculo decisivo à potência ontológica de "autodeterminação de outrem", tanto quanto à evidência descolonial da concomitante "heterodeterminação do si-mesmo" (Holbraad, Pedersen \& Viveiros de Castro, 2014). Desde o ponto de vista maximamente abstrato (e, como vimos, extremadamente etnocêntrico)

Não obstante, no que se refere à posição de Lévi-Strauss sobre o problema, é preciso considerar igualmente as teses avançadas em "As descontinuidades culturais e o desenvolvimento econômico e social" (publicado em 1963), ensaio no qual a perspectiva cosmopolita de "Raça e história" parece ser radicalmente posta em questão. Assim, ao contrário de interpretar a colonização do Novo Mundo como exemplo de coalizão entre culturas (logo, de progresso cultural), Lévi-Strauss acentua o caráter eminentemente destrutivo do desenvolvimento ocidental (a implicar a regressão cultural de outros povos): "Em primeiro lugar, as sociedades que hoje chamamos de 'subdesenvolvidas' não o são por si mesmas, e seria equivocado concebê-las como exteriores ao desenvolvimento ocidental ou como tendo permanecido indiferentes diante dele. Na verdade, foram essas sociedades que, por sua destruição entre os séculos XVI e XIX, tornaram possível o desenvolvimento do mundo ocidental. Entre elas e este a relação é de complementaridade. Foi o próprio desenvolvimento, com suas exigências vorazes, que as fez tais como ele mesmo as descobre atualmente. Não se trata, portanto, de um encontro entre dois processos que teriam ocorrido isoladamente um do outro. A relação de estranheza entre as sociedades ditas subdesenvolvidas e a civilização mecânica consiste sobretudo no fato de que nelas a civilização mecânica encontra seu próprio produto ou, mais precisamente, a contrapartida das destruições que cometeu no âmago delas para instaurar sua própria realidade. [...] 'Simplicidade' e 'passividade' não são atributos intrínsecos das culturas em questão, mas resultado da ação do desenvolvimento sobre elas, em seus primórdios. São uma situação criada pela brutalidade, pela pilhagem e pela violência, sem as quais as condições históricas desse desenvolvimento não teriam sido reunidas (se o tivessem sido de outro modo, a situação de contato teria sido totalmente diferente, completamente inimaginável para nós)" (Lévi-Strauss, 2013C, p. 348). 
oferecido pela ideia da universalidade do homem, ${ }^{14}$ o colonizado jamais pode ter garantida sua própria autonomia na determinação do que significa tornar-se humano, e o colonizador, por sua vez, se acha sempre autorizado a recusar a imagem monstruosa, desumana, de si que lhe é inexoravelmente devolvida.

Com efeito, em sentido de todo contrário à imaginação filosófica do povo universal, "a descolonização", diz Fanon,

nunca passa despercebida, pois diz respeito ao ser, ela modifica fundamentalmente o ser, transforma espectadores esmagados pela inessencialidade em atores privilegiados [...]. Ela introduz no ser um ritmo próprio, trazido pelos novos homens, uma nova linguagem, uma nova humanidade (Fanon, 2005, p. 52-53).

Enfim, a descolonização é metafísica porque faz explodir, com "violência absoluta" (idem), um mundo supostamente único, habitado exclusivamente pela humanidade cosmopolita, em "mundos múltiplos e divergentes" (Stengers, 2005, p. 995), constituídos por diferentes povos humanos.

Entretanto, essa glosa conclusiva, opondo-se à universalização como afeto primordial da metafísica do Ocidente colonizador, será por isso mesmo justa com a experiência dos povos sujeitados e sua luta de descolonização? Pelo menos, ela parece contradizer literalmente o diagnóstico mais completo de Fanon:

O contexto colonial, como dissemos, se caracteriza pela dicotomia que inflige ao mundo. A descolonização unifica esse mundo, retirando-lhe, por uma decisão radical, a sua heterogeneidade, unificando-a sobre a base da nação, algumas vezes da raça. Conhecemos as palavras ferozes dos patriotas senegaleses, evocando as manobras do presidente Senghor: "Nós pedimos a africanização dos quadros, e Senghor africaniza os europeus". O que quer dizer que o colonizado tem a possibilidade de perceber numa imediateza absoluta se a descolonização ocorre ou não: sendo o mínimo exigido que os últimos se tornem os primeiros (Fanon, 2005, p. 62-63).

Propondo, em lugar do mundo universal do colonizador, uma multiplicidade pretensamente descolonial, não se desconsidera assim a necessidade, preconizada por Fanon, da "unificação" do mundo colonizado contra aquele? Afinal de contas, o discurso sobre a multiplicidade

"O famoso princípio que pretende que todos os homens sejam iguais encontrará a sua ilustração nas colônias, logo que o colonizado afirmar que é igual ao colono. Um passo a mais e ele vai querer lutar para ser mais do que o colono. Na verdade, ele já decidiu substituir o colono, tomar-lhe o lugar. Como se vê, é todo um universo material e moral que desaba. O intelectual que seguiu o colonialista no plano do universal abstrato vai lutar para que colono e colonizado possam viver em paz num mundo novo. Mas o que ele não vê, porque precisamente o colonialismo se infiltrou nele com todos os seus modos de pensamento, é que o colono, logo que o contexto colonial desaparece, não tem mais interesse em ficar, em coexistir" (Fanon, 2005, pp. 61-62). 
e a divergência dos mundos não seria tão "sem lugar", feito como que desde nenhuma parte, quanto o discurso cosmopolita, o qual pretende se fazer desde todo lugar possível?

Talvez. Por outro lado, é certo que da unidade dicotômica do colonizador à unidade transformadora da descolonização há um enorme salto qualitativo: “O questionamento do mundo colonial pelo colonizado não é um confronto racional dos pontos de vista. Não é um discurso sobre o universal, mas a afirmação passional de uma originalidade apresentada como singularidade absoluta" (Fanon, 2005, p. 57). E é bem possível que esse salto, tendo por condição sine qua non a "explosão" do mundo colonial, ${ }^{15}$ conduza igualmente à superação cabal de sua metafísica - isto é, de sua forma de realizar a diferença ontológica de mundo -, com a substituição de toda e qualquer dicotomia entre povos por uma economia da alteridade inteiramente outra, mais próxima da afirmação daquela multiplicidade divergente que da universalidade pacificadora dos brancos: "[...] é preciso dirigir-se a outro lugar, e não à Europa" (idem, p. 366).

\section{"That's revolution"}

Gostaria de encerrar reportando um chamado de resistência e uma provocação contra-filosófica, oriundos de mundos bastante diferentes, mas tendo ambos em comum a catástrofe colonial.

Russell Means, pensador e líder político do povo Oglala Lakota, proferiu, em 1980, nas Colinas Negras da Dakota do Sul, um discurso ("The Same Old Song") no qual a tradição filosófica moderna é revista e criticada segundo um método de pensamento que, para usar um título caro à interpretação antropológica do pensamento ameríndio (Viveiros de Castro, 2002), poderíamos descrever como um " perspectivismo cosmológico" aplicado à colonialidade em geral: ${ }^{16}$

Há uma regra de ouro que pode ser empregada aqui. Não se pode julgar a natureza real de uma doutrina revolucionária européia em vista das mudanças que ela propõe realizar dentro da estrutura de poder e da sociedade européias. Somente é possível julgá-la pelos efeitos que ela tem sobre povos não-europeus. Isso porque toda revolução na história européia tem servido para reforçar as tendências e habilidades da Europa para exportar destruição a outros povos, a outras culturas e ao próprio ambiente. Desafio qualquer um a indicar um exemplo em que isso não seja verdadeiro (Means, 1983, p. 24).

"Explodir o mundo colonial é doravante uma imagem de ação muito clara, muito compreensível e que pode ser retomada por cada um dos indivíduos que constituem o povo colonizado. Desmantelar o mundo colonial não significa que, depois da abolição das fronteiras, serão construídas vias de passagem entre as duas zonas. Destruir o mundo colonial é, nem mais nem menos, abolir uma zona, enterrá-la no mais profundo do solo ou expulsá-la do território" (Fanon, 2005, p. 57). 
Após empreender, nessa chave perspectivística (pois aí, ao contrário do que deve suceder segundo o ideário cosmopolita, o juízo passa necessariamente pelo "ponto de vista de Outrem", irredutível a um ponto de convergência universal), um diagnóstico profundo e minucioso do pensamento europeu, Means conclui seu discurso com um chamado profético de resistência, princípio de uma revolução descolonial:

É apenas questão de tempo até que aconteça o que os europeus chamam de "uma catástrofe maior de proporções globais". É papel dos povos indígenas americanos, papel de todos os seres naturais, sobreviver. Parte de nossa sobrevivência é resistir. Resistimos não para derrubar um governo ou tomar o poder político, mas porque é natural resistir ao extermínio, sobreviver. Nós não queremos poder sobre as instituições brancas; nós queremos que as instituições brancas desapareçam. Isso é revolução (idem, p. 29).

Por fim, se o que entendemos e praticamos a título de filosofia, sobretudo na academia brasileira (de orientação ainda hoje fortemente colonialista), dificilmente abjura, no conteúdo e na forma do pensamento, a função de dispositivo para a aniquilação espiritual de outrem - mesmo que o outro, no caso, sejamos nós mesmos -, o que faremos da tão celebrada Filosofia?... Ouçamos, mais uma vez, Fanon, como se respondesse a essa antiga pergunta, saltando mortalmente por sobre um abismo que é tanto histórico e político quanto metafísico:

O que é que isso quer dizer? Simplesmente isso aqui: quando um antilhano diplomado em filosofia decide não concorrer para ser admitido como professor por causa de sua cor, digo que a filosofia nunca salvou ninguém. Quando um outro tenta obstinadamente me provar que os negros são tão inteligentes quanto os brancos, digo: a inteligência também nunca salvou ninguém, pois se é em nome da inteligência e da filosofia que se proclama a igualdade dos homens, também é em seu nome que se decide seu extermínio (Fanon, 2008, p. 42-43; trad. modif.).

\section{Referências}

BERNASCONI, R. Will the real Kant please stand up? The challenge of Enlightenment racism to the study of the history of philosophy. Radical Philosophy, n. 117, p. 13-22, 2003.

CÉSAIRE, A. Discurso sobre o colonialismo. Tradução de N. de Sousa. Lisboa: Sá da Costa Editora, 1978.

CLASTRES, P. Do etnocídio. In: P. Clastres. Arqueologia da violência: pesquisas de antropologia política. Tradução de P. Neves. São Paulo: Cosac Naify, 2003. p. 77-97. 
DELEUZE, G; GUATTARI, F. Ano zero - Rostidade. In: Deleuze, G; Guattari, F. Mil platôs: capitalismo e esquizofrenia, vol. 3. Tradução de A. Guerra Neto et alli. Rio de Janeiro: Editora 34, 1996. p. 31-61.

EZE, E. C. The Color of Reason: The Idea of 'Race' in Kant's Anthropology. In: Eze, E. C. (Org.). Postcolonial African Philosophy: A Critical Reader. Cambridge, Oxford: Blackwel, 1997. p. 103-140.

FANON, F. Peau noire, masques blancs. Paris: Éditions du Seuil, 1952.

Os condenados da terra. Tradução de E. A. Rocha e L. Magalhães. Juiz de Fora: Ed. UFJF, 2005.

Pele negra, máscaras brancas. Tradução de R. da Silveira. Salvador: EDUFBA, 2008.

GONÇALVES, P. A. P. Universalidade exclusiva: o racismo em Kant. Monografia de conclusão de curso. Curitiba: Departamento de Filosofia/UFPR, 2015.

HILL, T.; BOXILL, B. Kant and Race. In: B. Boxhill (Org.). Race and Racism. Oxford: Oxford University Press, 2000. p. 448-471.

HOLBRAAD, M.; PEDERSEN, M. A.; VIVEIROS DE CASTRO, E. "The Politics of Ontology: Anthropological Positions". Fieldsights - Theorizing the Contemporary, Cultural Anthropology Online. 2014. Disponível em: http:/ / culanth.org/ fieldsights / 462-the-politics-of-ontology-anthropological-positions.

KANT, I. Gesammelte Schriften, Band XV: Handschriftlicher Nachlass, II-2: Anthropologie. Herausgegeben von der Königlich Preussischen Akademie der Wissenschaften. Berlin, Leipzig: Walter de Gruyter, 1923.

. Crítica da razão pura (Os Pensadores). Tradução de V. Rohden e U. B. Moosburger. São Paulo: Abril Cultural, 1980.

Crítica da faculdade do juízo. Tradução de V. Rohden e A. Marques. Rio de Janeiro: Forense Universitária, 2002.

À paz perpétua. Tradução de M. Zingano. Porto Alegre: L\&PM, 2008.

LATOUR, B. Jamais fomos modernos: ensaio de antropologia simétrica. Tradução C. I. da Costa. Rio de Janeiro: Editora 34, 1994. 
. War of the Worlds: What about Peace? Translated by C.

Biggs. Chicago: Prickly Paradigm Press, 2002.

Lévi-Strauss, C. O pensamento selvagem. Tradução de T. Pellegrini. Campinas: Papirus, 1989.

. Jean-Jacques Rousseau, fundador das ciências do homem.

In: C. LÉVI-STRAUSS, Antropologia estrutural dois. Tradução de B. Perrone-Moisés. São Paulo: Cosac Naify, 2013a. p. 45-55.

. Raça e história. In: C. LÉVI-STRAUSS, Antropologia estrutural dois. Tradução de B. Perrone-Moisés. São Paulo: Cosac Naify, 2013b. p. 357-399.

. As descontinuidades culturais e o desenvolvimento econômico e social. In: C. LÉVI-STRAUSS, Antropologia estrutural dois. Tradução de B. Perrone-Moisés. São Paulo: Cosac Naify, 2013c. p. 345-356.

MALDONADO-TORRES, N. A topologia do Ser e a geopolítica do conhecimento: modernidade, império e colonialidade. Revista Crítica de Ciências Sociais, n. 80, p. 71-114, 2008.

MEANS, R. The Same Old Song. In: W. CHURCHILL (Org.). Marxism and Native Americans. Boston: South End Press, 1983. p. 19-34.

MILLS, C. "Kant's Untermenschen". In: A. VALLS (Org.). Race and Racism in Modern Philosophy. Ithaca, London: Cornell University Press, 2005. p. 169-193.

SARTRE, J.-P. Prefácio à edição de 1961. In: F. FANON. Os condenados da terra. Tradução de E. A. Rocha e L. Magalhães. Juiz de Fora: Ed. UFJF, 2005. p. 23-48.

STENGERS, I. The Cosmopolitical Proposal. In: B. LATOUR; P. WEIBEL (Org.). Making Things Public: Atmospheres of Democracy. Cambridge: MIT Press, 2005. p. 994-1003.

TERRA, R. R. Les observations de Kant sur les races affectent-elles l'universalisme de sa philosophie?. In: L. R. dos SANTOS; U. R. de A. MARQUES; G. PIAIA; M. SGARBI; R. POZZO (Orgs.). Was ist der Mensch? / Que é o homem - Antropologia, estética e teleologia em Kant. Lisboa: CFUL, 2010. p. 139-150.

VALENTIM, M. A. Extramundanidade e sobrenatureza. Natureza Humana, v. 15, n. 2, p. 48-93, 2013. 
VIVEIROS DE CASTRO, E. Perspectivismo e multinaturalismo na América indígena. In: E. VIVEIROS DE CASTRO. A inconstância da alma selvagem - e outros ensaios de antropologia. São Paulo: Cosac Naify, 2002. p. 345-399.

. No Brasil todo mundo é índio, exceto quem não é. In: R.

SZTUTMAN (Org.). Encontros - Eduardo Viveiros de Castro. Rio de Janeiro: Beco do Azougue, 2008. p. 132-161.

Metafísicas canibais: elementos para uma antropologia pós-estrutural. São Paulo: Cosac Naify, 2015. 